Western University Scholarship@Western

1985

\title{
Adjustment Costs and Capital Asset Pricing
}

Gregory W. Huffman

Follow this and additional works at: https://ir.lib.uwo.ca/economicsresrpt

Part of the Economics Commons

Citation of this paper:

Huffman, Gregory W.. "Adjustment Costs and Capital Asset Pricing." Department of Economics Research Reports, 8502. London, ON: Department of Economics, University of Western Ontario (1985). 
IS BN :

ISSN :

RESEARCH REPORT 8502

\section{ADJUSTMENT COSTS AND CAPITAL \\ ASSET PRICING}

by

Gregory W. Huffman

January, 1985

Forthcoming in Journal of Finance.

Deportment of Economics Library

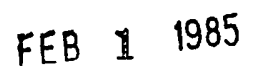

University of Western Ontario 


\section{INTRODUCTION}

There is a growing literature in economics which seeks to study the factors which influence the prices of assets within the context of discrete-time optimization models. A popular approach is to study the optimization problem faced by a "representative agent". An example. of this type of procedure is that described by Lucas [18]. Within this paradigm, it is assumed that there exists a representative agent who maximizes a discounted sum of instantaneous utilities

$$
E_{t} \sum_{i=0}^{\infty} \beta^{t} U\left(o_{t+i}\right),(0<\beta<1)
$$

subject to the constraints

$$
c_{t}+P_{t} \cdot k_{t} \leqq\left(P_{t}+r_{t}\right) \cdot k_{t-1}{ }^{1}
$$

where $\quad c_{t}=$ consumption at date $(t)$,

$$
\begin{aligned}
P_{t}= & \text { price of the asset at date }(t), \\
k_{t}= & \text { quantity of the asset held at the end of period }(t), \\
r_{t}= & \text { dividend or yield of the asset, in units of the consumption good, } \\
& \text { at date }(t) \\
E_{t}(\cdot)= & \text { expectation operator, conditional on all information available } \\
& \text { at date }(t) .
\end{aligned}
$$

With appropriate side conditions, the necessary condition for the solution to the agent's optimization is, as is well known,

$$
P_{t} U^{\prime}\left(c_{t}\right)=\beta E_{t}\left\{\left(P_{t+1}+r_{t+1}\right) U^{\prime}\left(c_{t+1}\right)\right\} \text {. }
$$

Through existing techniques, it can be shown that there exists a function relating the state variables in the economy at any date to the price of capital at that date. This type of equilibrium model is useful in that it relates the way in which asset prices may change when there is a change in, say, dividends, non-capital income, or risk aversion.

When $U\left(c_{t}\right)=c_{t}$, and hence the representative agent is risk-neutral, equation (3) becomes 


$$
P_{t}=E_{t} \sum_{i=1}^{\infty}\left(\beta^{i}\right)\left(r_{t+i}\right),
$$

which is the conventional asset pricing formula employed by LeRoy and Porter [17], and Shiller [24] in the study of stock price variability. There is a sense in which this particular model is deficient in that agent's marginal rates of substitution may change over time. Consequently, the rates at which future dividends are discounted may change.

LeRoy and LaCivita [16] have used a more general form of equation (3) to study the effects of risk aversion on asset prices. Similarly, Prescott and Mehra [21] have used this model to analyze the risk premia.

As has been documented elsewhere (for example, see Huffman [9]), the infinitely-lived representative agent models of asset pricing have not been wholly successful in mimicking certain stylized facts. This has in turn led others to construct alternative models which give rise to different methods for pricing capital assets (see Bewley [1]; Huffman [9], [10], 111]; Huberman [8]; Scheinkman and Weiss [23]). This paper is yet another contribution to this literature.

It is the thesis of this paper that the price of a particular capital asset should reflect the preferences of agents as well as the natural underlying technology of the economy. Further, it is not necessary that the latter be trivial. The technology present in the economy described by equations (1) and (2) is primitive: capital is not depreciable nor augmentable, and it yields an exogenous return each period. Elsewhere, asset pricing formulas with a simple technology for accumulation have been constructed (see Huffman [9]). The model constructed in this paper will employ a non-trivial technology for accumulating capital which will give rise to a stationary asset pricing formula for capital which depends, In an interesting manner, on the existing state variables of the economy. In particular, the presence of augmentable capital combined adjustment costs in investment significantly alters the way in which existing capital is priced. In addition, 
the model described below will be an infinite horizon economy in which each agent lives for a finite number of periods. In fact, the solutions to the consumer's optimization problem will be tractable if each agent lives for just two periods. This device lends to the model the flavor of a heterogeneous population (this stands in contrast to the infinitely-lived representative agent paradigm which presumes that heterogeneity is not important). With an economy of heterogeneous agents it is possible, as will be shown, to have agents purchasing assets in one period and selling them in a subsequent period. It may then be of interest to inquire as to whether this characteristic implies any interesting behavior for asset prices.

The remainder of this paper is organized as follows. In Section II the precise nature of the economy is described. Each period there will appear a new generation of two-period lived agents. These agents may purchase capital from members of the previous generation and may also, through a non-trivial technology, produce more capital. Capital is productive in that it yields a dividend, in units of the consumption good, each period. Section III will contain two examples of the economies described in the previous section, which possess different technologies with which individuals can undertake investment. The behavior of the price of capital as well as that of aggregate consumption and investment will be described. Section IV will describe the role of the finite-time horizon in models of this sort. Conclusions are presented in Section $\mathrm{V}$.

\section{The Physical Environment}

This section describes an economy in which time is discrete and at each date $t$, for $t \geqq 1$, there are born $N$ identical two-period-lived agents. An agent who is present in the economy in periods $(t)$ and $(t+1)$ is said to be a member of generation $(t)$. Each member of generation $(t)$ is endowed with $w_{t}$ units of the homogeneous consumption good in period $(t)$ and has no endowment in period $(t+1)$. Such an agent 
consumes $c_{t}^{1}$ units of the consumption good in period $(t)$ and $c_{t}^{2}$ units of the consumption good in period $(t+1)$. Members of generation ( $t$ ) each maximize the identical, separable, strictly concave, differentiable utility function $U\left(c_{t}^{1}\right)+V\left(c_{t}^{2}\right)$. Also let

$$
\lim _{x \rightarrow 0} U^{\prime}(x)=\lim _{x \rightarrow 0} V^{\prime}(x)=\infty \text {. }
$$

Since all members of a single generation are identical, no generality is lost in assuming $\mathrm{N}=1$.

At any date $(t)$, there exists $k_{t}$ units of capital which was brought forth from period $(t-1)$ by the members of generation $(t-1)$. At time $t=1$, there exists $k_{0}>0$ units of capital in the economy held by an existing one-period-1ived generation who wish to maximize consumption in period one. Capital cannot be transformed into the consumption good, but there exists a technology for converting the consumption good into capital. An agent who is a member of generation ( $t$ ) can devote $x_{t} \geqq 0$ units of his or her endowment to the production of capital, and this in turn yields $\Psi\left(\alpha_{t}, x_{t}\right)$ units of capital which becomes productive at the beginning of period $(t+1)$. $\alpha_{t}$ is merely a technological shock which is known at the beginning of period $(t) . \Psi\left(\cdot, x_{t}\right)$ represents the technology for converting the consumption good into capital (see Figure 1 ). It is assumed that $\Psi(\cdot, \cdot)$ is concave, differentiable, and that

$$
\begin{array}{r}
\Psi(\bar{\alpha}, \mathbf{x}) \geqq 0 \\
\Psi(\bar{\alpha}, 0)=0 \\
\frac{\partial \Psi(\bar{\alpha}, \mathbf{x})}{\partial \mathbf{x}}>0
\end{array}
$$

for all $\mathrm{x} \geqq 0$ and all $\bar{\alpha}$ which occur with positive probability. $\Psi(\cdot, \cdot)$ is referred to by Hayashi [7] as an installation function. Its concavity reflects the adjustment costs inherent in producing capital: larger quantities of investment induce higher marginal costs of producing capital. It will be of interest to see how these adjustment costs are reflected in the price of existing capital. 
Capital brought into period $(t)$ yields an exogenous dividend of $\left(r_{t}\right)$ per unit of capital. Productive capital depreciates at the rate $\delta$ per period, where $0 \leqq \delta \leqq 1$

The problem posed to a member of generation ( $t$ ) is to

$$
\operatorname{maximize} U\left(c_{t}^{1}\right)+E_{t}\left[V\left(c_{t}^{2}\right)\right]
$$

subject to the constraints

$$
\begin{aligned}
& c_{1}^{t}=w_{t}-P_{t} k_{t}-x_{t} \\
& c_{2}^{t}=P_{t+1}\left(k_{t}+\Psi\left(\alpha_{t}, x_{t}\right)\right)(1-\delta)+\left(k_{1}+\Psi\left(\alpha_{t}, x_{t}\right)\right) r_{t+1}
\end{aligned}
$$

where $P_{t+1}$ and $r_{t+1}$ are unknown at time $(t)$. As well, the equation governing the capital stock is

$$
k_{t+1}=\left(k_{t}+\Psi\left(\alpha_{t}, x_{t}\right)\right)(1-\delta)
$$

The state vector for this economy at any date $(t)$ is $\left(w_{t}, \alpha_{t}, r_{t}, k_{t}\right) \cdot k_{t}$ is clearly detennined by the decisions of agents in conjunction with equation (6:). It is assumed-that the variables $\left(w_{t}, \alpha_{t}, r_{t}\right)$ are observed prior to the appearance of members of generation $(t)^{2}$ and that this vector is distributed over some interval $[\underline{\underline{w}}, \bar{w}] \times[\underline{\alpha}, \bar{\alpha}] \times[\underline{\underline{r}}, \overline{\mathrm{r}}] \in \Omega_{++}^{3}$. It is assumed that this distribution is stationary and that agents utilize the same distribution when solving their optimization problem.

The necessary conditions for the solution to the agent's optimization problem are

$$
\begin{aligned}
P_{t} U^{\prime}\left(c_{t}^{1}\right) & =E_{t}\left\{V^{\prime}\left(c_{t}^{2}\right)\left(P_{t+1}(1-\delta)+r_{t+1}\right)\right\} \\
U^{\prime}\left(c_{t}^{2}\right) & \geqq E_{t}\left\{V^{\prime}\left(c_{t}^{2}\right)\left(P_{t+1}(1-\delta)+r_{t+1}\right) \frac{\partial \Psi\left(\alpha_{t}, x_{t}\right)}{\partial x_{t}}\right\}
\end{aligned}
$$

Equation (8) holds with equality if $x_{t}>0$. Since $\alpha_{t}$ is known at time ( $t$ ), then $x_{t}>0 \Rightarrow P_{t}\left[\frac{\partial \Psi\left(\alpha_{t}, x_{t}\right)}{\partial x_{t}}\right]=1$

and 


$$
\left[\frac{\partial \Psi\left(\alpha_{t}, x_{t}\right)}{\partial x_{t}}\right]>P_{t} \Rightarrow x_{t}=0
$$

$\left[\frac{\partial \Psi\left(\alpha_{t}, x_{t}\right)}{\partial x_{t}}\right]^{-1}$ should be interpreted as the marginal cost of producing an extra

unit of capital and these equations imply that the price of existing capital should be positively correlated with this marginal cost. It is also clear that the price of capital can fall below this marginal cost, but only if

$$
\left.\frac{\partial \Psi\left(\alpha_{t}, x_{t}\right)}{\partial x_{t}}\right|_{x_{t}=0}<\infty .
$$

The solution of equations (4)-(8) for a pricing function which relates the price of capital to the state vector may be a non-trivial task in general. However, with suitable restrictions, existing theoretical methods could almost certainly be applied to prove that an equilibrium exists for a restricted class of economies. Since the primary purpose of this paper is illustrative, the next section will forsake generality and instead make use of precise examples.

\section{Two Examples}

In this section the environment is specified in such a way that solutions may be obtained for the investment and pricing functions in this economy. It will be assumed that the utility function takes the form

$$
U\left(c_{t}^{1}\right)+V\left(c_{t}^{2}\right)=\ln \left(c_{t}^{1}\right)+\ln \left(c_{t}^{2}\right)
$$

In the following two examples, two different installation functions are employed to arrive at different pricing and investment functions.

Example 1: It is assumed that

$$
\Psi\left(\alpha_{t}, x_{t}\right)=\left(1 / \alpha_{t}\right)\left(x_{t}\right)^{\frac{1}{2}}
$$

Equations (7) and (8) now take the form 


$$
\begin{aligned}
& \left\{\frac{P_{t}}{w_{t}-P_{t} k_{t}-x_{t}}\right\}=E_{t}\left\{\frac{\left(P_{t+1}(1-\delta)+r_{t+1}\right)}{P_{t+1}(1-\delta)\left(k_{t}+\left(1 / \alpha_{t}\right) \sqrt{x_{t}}\right)+\left(k_{t}+\left(1 / \alpha_{t}\right) \sqrt{x_{t}}\right) r_{t+1}}\right\} \\
& \left\{\frac{1}{w_{t}-P_{t} k_{t}-x_{t}}\right\} \geqq E_{t}\left\{\frac{\left(P_{t+1}(1-\delta)+r_{t+1}\right)\left(1 / 2 \alpha_{t}\right)\left(x_{t}\right)^{-\frac{1}{2}}}{P_{t+1}(1-\delta)\left(k_{t}+\left(1 / \alpha_{t}\right) \sqrt{x_{t}}\right)+\left(k_{t}+\left(1 / \alpha_{t}\right) \sqrt{x_{t}}\right) r_{t+1}}\right\}
\end{aligned}
$$

Multiplication of equation (11) by $\left(2 \alpha_{t} \sqrt{x_{t}}\right)$, together with equation (10) yields

$$
\left(2 \alpha_{t} \sqrt{x_{t}}\right) \geqq P_{t}
$$

This in turn implies that both equations (11) and (12) hold with equality. Were this not so, $x_{t}=0$ would imply $P_{t}=0$ and so productive capital would not be held, even when preferences were strictly increasing. This is obvious when one considers that the installation function in equation (9) has infinite marginal product at $x_{t}=0$; hence capital will be produced each period (see Figure 2). Further examination of equation (9) shows that the marginal cost of producing more capital when $\bar{x}$ units of the consumption good have already been devoted to its production, is in fact, $\left(2 \alpha_{t} \sqrt{x_{t}}\right)$. Hence the marginal cost of capital is increasing in the amount of investment undertaken. (This is also clear from Figures 1 and 2.) Further, in this instance the value for Tobin's "q" is defined as

$$
q \equiv \frac{\text { price of existing capital }}{\text { marginal cost of producing new capital }}=\frac{\mathrm{P}_{t}}{\left(2 \alpha_{t} \sqrt{\mathrm{x}_{t}}\right)}=1 \text {, }
$$

with the last equality following because equation (12) holds with equality. Hence $\mathrm{q}=1$ and investment is positive in each period.

Multiplication of equation (10) by $k_{t}$ and of equation (11) by $\left(2 x_{t}\right)$ implies

$$
\frac{2 x_{t}+P k_{t}}{w_{t}-x_{t}-P_{t} k_{t}}=1
$$

Equations (13) and (12) with equality yield the following reduced forms for the pricing and investment functions for this economy:

$$
P_{t}=\left(\frac{2 \alpha_{t}^{2}}{3}\right)\left(-2 k_{t}+\left(4 k_{t}^{2}+\frac{3 w_{t}}{\alpha_{t}^{2}}\right)^{\frac{1}{2}}\right)
$$




$$
x_{t}=(1 / 6)\left(-2 k_{t}+\left(4 k_{t}^{2}+\left(w_{t} / \alpha_{t}^{2}\right)\right)^{\frac{1}{2}}\right)
$$

The solutions for $\mathrm{P}_{t}$ and $\mathrm{x}_{t}$ are solutions to a polynomial, which is a reflection of the similar nature of the installation function in equation (9). Utilizing equations (6) and (15), there is also a reduced form function which describes the level of the capital stock as a function of the state variables.

Equations (14) and (15) do not lend themselves in a tractable manner to calculation of summary statistics. For this reason, examples have been calculated for a particular specification of the environment, and such economies are presented in Tables 1 and 2 . Table 1 contains an example in which endowments fluctuate randomly, and may be thought of as illustrating the effects of changes in income. Table 2 contains an example in which the installation function displays random shifts, and this may be interpreted as a technological shock. In both cases the average price of capital is higher when the depreciation rate is higher. This stands to reason: as capital depreciates faster, more investment will be undertaken, which in turn will drive up the cost of producing new capital as well as the price of existing capital. Also, each unit of capital is naturally valued higher when it depreciates faster. There is also an interesting relationship between the measures of variability of the different variables, and the depreciation rate.

Lastly, it is of interest to note that the dividend yielded by capital each period is constant and the variability in prices is induced through other factors.

Example 2: In this example it is assumed that the installation function takes the form

$$
\Psi\left(\alpha_{t}, x_{t}\right)=\ln \left(\alpha_{t}+x_{t}\right)-\ln \left(\alpha_{t}\right)
$$

This will provide an interesting contrast with the first example because $\frac{\partial \Psi\left(\alpha_{t}, x_{t}\right)}{\partial x_{t}}<\infty$ for all $\alpha_{t}>0$ in this instance. This was not the case in the first example. 
Table $1^{3}$

$$
\alpha=1.0 \quad r=1.0 \quad \Psi(x)=(1 / \alpha)(x)^{\frac{1}{2}}
$$

Probability Distribution of $\mathrm{w}$

\begin{tabular}{|c|c|c|c|c|}
\hline & $\underline{\mathbf{w}}$ & & bility & \\
\hline & 10 & & $/ 2$ & \\
\hline & 5 & & 12 & \\
\hline$\delta$ & $\overline{\mathrm{p}}$ & $\rho(P)$ & $\rho(c)$ & $\rho(x)$ \\
\hline .02 & .509 & .328 & .168 & .595 \\
\hline .05 & .686 & .324 & 190 & .592 \\
\hline .10 & .857 & .321 & .207 & .593 \\
\hline .25 & 1.140 & .320 & .228 & .604 \\
\hline
\end{tabular}

Definition of Symbols

$\rho(P)=$ coefficient of variation of the price of capital

$\rho(c)=$ coefficient of variation of aggregate consumption

$\rho(x)=$ coefficient of variation of investment

$\overline{\mathrm{P}} \quad=$ average price of capital

Table 2

$$
w=10.0 \quad r=1.0 \quad \Psi(\alpha, x)=(1 / \alpha)(x)^{1 / 2}
$$

\section{Probability Distribution of $\alpha$}

$\underline{\alpha}$

2.0

0.5

$\frac{\delta}{.02} \quad \frac{\overline{\mathrm{p}}}{.431}$

$.05 \quad .582$

$.10 \quad .730$

$.25 \quad .979$
Probability

$1 / 2$

$1 / 2$

$\rho(\mathrm{P}) \quad \underline{\rho(c)} \quad \underline{\rho(x)}$

$\begin{array}{lll}.052 & .024 & .582\end{array}$

$\begin{array}{lll}.065 & .031 \quad .562\end{array}$

$.089 \quad .042 \quad .543$

$\begin{array}{lll}.137 & .069 & .504\end{array}$ 
Equations (7) and (8) take the form

$$
\begin{aligned}
& \left\{\frac{P_{t}}{w_{t}-P_{t} k_{t}-x_{t}}\right\}=E_{t}\left\{\frac{\left(P_{t+1}(1-\delta)+r_{t+1}\right)}{P_{t+1}(1-\delta)\left[k_{t}+\ln \left(\alpha_{t}+x_{t}\right)-\ln \left(\alpha_{t}\right)\right]+\left[k_{t}+\ln \left(\alpha_{t}+x_{t}\right)-l_{n}\left(\alpha_{t}\right)\right] r_{t}}\right\} \\
& \left\{\frac{1}{w_{t}-P_{t} k_{t}-x_{t}}\right\} \geqq E_{t}\left\{\frac{\left(P_{t+1}(1-\delta)+r_{t+1}\right)\left(\frac{1}{\left.\alpha_{t}+x_{t}\right)}\right.}{P_{t+1}(1-\delta)\left[k_{t}+\ln \left(\alpha_{t}+x_{t}\right)-\ln \left(\alpha_{t}\right)\right]+\left[k_{t}+\ln \left(\alpha_{t}+x_{t}\right)-\ln \left(\alpha_{t}\right)\right] r_{t}}\right\}
\end{aligned}
$$

Multiplication of equation (18) by $\left(\alpha_{t}+x_{t}\right)$, together with equation (17) implies

$$
\left(\alpha_{t}+x_{t}\right) \geqq P_{t}
$$

This implies a pattern of prices and investment as illustrated in Figure 3 . In contrast to the previous example, it is not the case that investment will always be undertaken in the present economy. If $x_{t}=0$, then $\alpha_{t} \geqq P_{t} \cdot$ In statistical terms, the origin serves as a reflecting barrier for investment and a time varying value, namely $\left(\alpha_{t}+x_{t}\right)$, serves as a reflecting barrier for the price of capital.

Examination of equation (16) shows that the marginal product of producing more capital, when $\bar{x}$ units of the consumption good have already been devoted to this production, is $\left(\alpha_{t}+\bar{x}\right)$, which is again increasing in the amount of investment. In this case Tobin's "q" is defined as

$$
q=\left(\frac{P_{t}}{\alpha_{t}+x_{t}}\right) \leqq 1 .
$$

Because of the nature of equation (18), " $q$ " will be non-decreasing in $x_{t}$. This is because of the familiar relationship between investment and Tobin's "q" which obtains in this case:

$$
\begin{gathered}
q<1 \Rightarrow x_{t}=0 \\
x_{t}>0 \Rightarrow q=1
\end{gathered}
$$

When $x_{t}=0$, equation (17) implies that

$$
P_{t}=\left(\frac{w_{t}}{2 k_{t}}\right) \leqq \alpha_{t} .
$$

When $x_{t}>0$, then by multiplying equation (17) by $k_{t}$ and equation (18) by $\left(\alpha_{t}+x_{t}\right)\left(\ln \left(\alpha_{1}+x_{t}\right)-\ln \left(\alpha_{t}\right)\right)$ yields 


$$
\left(\frac{\left(\alpha_{t}+x_{t}\right)\left(\ln \left(\alpha_{t}+x_{t}\right)-\ln \left(\alpha_{t}\right)\right)+P_{t} k_{t}}{w_{t}-P_{t} k_{t}-x_{t}}\right)=1
$$

and hence employing equation (19) at equality yields

$$
\begin{aligned}
& \left(\alpha_{t}+x_{t}\right)\left[\ln \left(\alpha_{t}+x_{t}\right)-\ln \left(\alpha_{t}\right)+2 k_{t}\right]+x_{t}=w_{t} \\
& \left(P_{t}\right)\left[\ln \left(P_{t}\right)-\ln \left(\alpha_{t}\right)+2 k_{t}\right]+P_{t}-\alpha_{t}=w_{t} .
\end{aligned}
$$

The equilibrium investment function for this economy can then be written as

$$
x_{t}=\max \left\{0, g\left(k_{t}, \alpha_{t}, w_{t}\right)\right\},
$$

where $g(\cdot, \cdot, \cdot)$ is defined implicitly by solving equation $(20)$ for $x_{t} \cdot$ Further, it is clear that $g_{1}<0, g_{2}<0$, and $g_{3}>0$. This represents the conventional notion that investment is non-decreasing in the quantity of existing capital and the cost of producing capital. As well, investment is an increasing function of the level of individual non-capital wealth $\left(w_{t}\right)$.

Similarly, the equilibrium pricing formula for capital can be written as

$$
P_{t}=\min \left\{h\left(k_{t}, \alpha_{t}, w_{t}\right),\left(\frac{w_{t}}{2 k_{t}}\right)\right\}
$$

where $h(\cdot, \cdot, \cdot)$ is defined implicitly by equation (21). It is also clear that $h_{1}<0$, $h_{2}>0, h_{3}>0$. Also equations (20) and (21) show that

$$
h\left(k_{t}, \alpha_{t}, w_{t}\right) \equiv g\left(k_{t}, \alpha_{t}, w_{t}\right)+\alpha_{t}
$$

Tables 3, 4 and 6 contain examples of economies which use the type of installation function described by equation (16). In addition to those statistics, Tables 3-6 contain an additional column specifying the percentage of the time that investment is not undertaken. This is possible because the installation function in equation (16) has finite marginal product at $\mathbf{x}_{t}=0$.

Table 3 presents the results for this economy when there are endowment shocks. As in all these examples, the average level of capital prices and the variability of consumption are positively related to the depreciation rate of capital.

Tables 3 and 4 provide an interesting contrast. These economies are identical with the exception that the marginal product of the installation function, when $x_{t}=0$, in the economy for Table 4 is twice that for the economy descrived by Table 3. In 
$\underline{\text { Table } 3}$

$$
\alpha=1.0 \quad r=1.0 \quad \Psi(\alpha, x)=\ln (\alpha+x)-\ln (x)
$$

Probability Distribution of $w$

\begin{tabular}{|c|c|c|c|c|c|}
\hline & & $\underline{w}$ & Probab: & ity & \\
\hline & & $\begin{array}{r}10 \\
5\end{array}$ & $\begin{array}{l}1 / 2 \\
1 / 2\end{array}$ & & \\
\hline$\underline{\delta}$ & $\underline{\overline{\mathbf{P}}}$ & $\underline{e(P)}$ & $p(c)$ & $\rho(x)$ & $\begin{array}{c}\% \text { of time } \\
x=0\end{array}$ \\
\hline .02 & .907 & .275 & .217 & 1.06 & $50 \%$ \\
\hline .05 & 1.06 & .259 & .225 & 1.07 & 49.9 \\
\hline .10 & 1.24 & $.253^{\circ}$ & .232 & 1.05 & 46 \\
\hline .25 & 1.50 & .273 & .246 & .900 & 25 \\
\hline
\end{tabular}

Table 4

$$
\alpha=0.5 \quad r=1.0 \quad \Psi(\alpha, x)=\ln (\alpha+x)-\ln (\alpha)
$$

Probability Distribution of w

w $\quad$ Probability

$10 \quad 1 / 2$

$5 \quad 1 / 2$

$\underline{\delta} \quad \underline{\underline{\mathbf{P}}} \quad \underline{\rho(\mathrm{P})} \quad \underline{\rho(c)} \quad \underline{\rho(\mathrm{x})} \quad$\begin{tabular}{l}
$\begin{array}{l}\% \text { of time } \\
x=0\end{array}$ \\
\hline
\end{tabular}

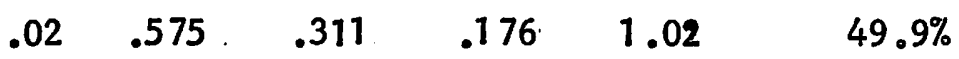

$\begin{array}{llllll}.05 & .735 & .296 & .194 & .901 & 13.0\end{array}$

$\begin{array}{llllll}.10 & .878 & .292 & .211 & .679 & 0.0\end{array}$

$\begin{array}{llllll}.25 & 1.15 & .290 & .237 & .514 & 0.0\end{array}$ 
other words, the adjustment costs of investment are higher for the first economy than for the second. Consequently, the average price of capital is higher in the economy with high adjustment costs: since adding to the capital stock is more costly, existing capital will have a higher value. Also, the price of capital appears to have more variability in the economy with lower adjustment costs. However, consumption and investment are more variable in the economy with higher adjustment costs. An interesting question would appear to be whether investment is undertaken more often in an economy with high adjustment costs. A comparison of the last columns in Tables 3 and 4 reveals that investment is undertaken less often in the economy with higher adjustment costs. In fact, for the economy with low adjustment costs (Table 4) and sufficiently high depreciation rates, investment will always be undertaken.

Tables 4 and 5 also provide an interesting comparison. Table 4 utilizes the installation function from equation (16) whilst Table 5 uses the following form:

$$
\Psi\left(\alpha_{t}, x_{t}\right)=(2 x) \text {. }
$$

With the exception of this change, both economies are identical. This comparison is of interest because the marginal products of both installation functions equal 2 when $x_{t}=0$. However, equation (16) displays increasing marginal cost, whilst equation (22) displays constant marginal cost. A comparison of this type highlights the effects that adjustment costs play in this analysis. The average price of capital, for those two examples, is higher in the economy with adjustment costs. The variability of the price of capital is likely to be greater for the economy with adjustment costs if the depreciation rate is also high. However, consumption appears to be more variable while investment is less variable in the economy with adjustment costs. The reason is clear: the adjustment costs deter large variations in investment and consequently consumption absorbs more variability. That adjustment costs have an effect on how often investment is undertaken should also be clear from a comparison of the last columns in Tables 4 and 5. The frequency with which investment is not undertaken is influenced more by the depreciation rate in the presence of adjustment costs. 
Tab1e 5

$$
\alpha=0.5 \quad r=1.0 \quad \Psi(\alpha, x)=\left(\frac{1}{\alpha}\right) \mathrm{x}
$$

Probability Distribution of $w$

$\begin{array}{cc}\frac{w}{10} & \text { Probability } \\ 5 & 1 / 2 \\ & 1 / 2\end{array}$

\begin{tabular}{|c|c|c|c|c|c|}
\hline$\delta$ & $\overline{\mathbf{p}}$ & $\rho(P)$ & $\rho(c)$ & $\rho(x)$ & $\begin{array}{l}\% \text { of Time } \\
x=0\end{array}$ \\
\hline .02 & .380 & .316 & 139 & 1.43 & $50 \%$ \\
\hline .05 & .388 & .290 & .140 & 1.38 & 49.9 \\
\hline .10 & .403 & .255 & .159 & 1.35 & 49.2 \\
\hline .25 & .435 & .194 & .236 & 1.15 & 38 \\
\hline
\end{tabular}

Table 6

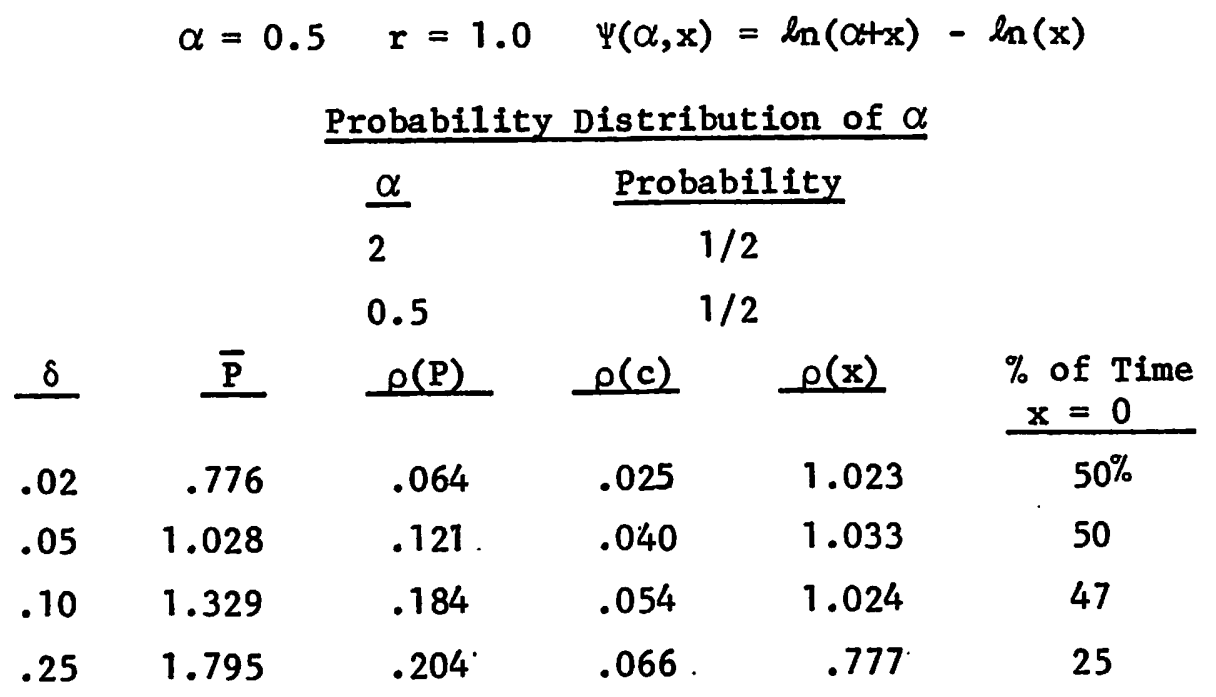


Lastly, Table 6 illustrates an economy with the installation function shown in equation (16), combined with technological shocks to this function.

There are several notable factors concerning all these examples. First, there has not been any need to consider variability in the dividend yielded by capital $\left(r_{t}\right)$. If such variability were added, investment and prices would not be affected, but aggregate consumption would be altered. Secondly, all these examples are consistent with the notion that variability in investment is much greater than that in aggregate consumption. Thirdly, the percentage of the time in which investment is positive is a non-decreasing function of the depreciation rate for capital. Lastly, in many of the examples which make use of a nonlinear installation function, there is not a strict monotonic relationship between the depreciation rate and all the average and variability: measures displayed in the tables. Hence, it would seem that the non-linearity induced in the pricing and investment functions by the curvature of the installation function produces an interesting (but possibly complicated) relationship between the price of capital and the state variables of the economy.

\section{Importance of the Planning Horizon}

The preceding analysis was undertaken with precise specification for the utility and installation functions. These in turn led to tractable functional forms for the pricing and investment functions. Since generality was not the goal of this paper, an entirely appropriate issue to be raised concerns the robustness of these results. This is difficult to answer because of the complexity of the environment that one could potentially employ. In particular though, one might inquire about the necessity of having agents live for only two periods.

Casual investigation reveals that, though certainly solvable in theory, the study of asset pricing with augmentable capital in a model of, say, infinitely-lived agents

- does not lend itself to easily interpretable solutions. Hence, the two-period paradigm was utilized in this paper because of its tractability. ${ }^{4}$ With the preceding analysis in mind, it is possible now to conjecture about how asset prices might behave in a model in which agents live for more than two periods. 
One might wish to interpret the asset market, like any other market, simply as composed of supply and demand curves. In fact, the model described by equations (1) and (2) with, say $k_{t}=1$ for all $t$, can be interpreted as being composed of supply and demand curves (see Figure 4). The (compensated) supply curve can be interpreted as that price of capital that would have to be paid to the representative agent to make him on her indifferent between the present portfolio, and selling another unit of capital, when they presently hold $k$ units of the asset. Similarly, the (compensated) demand curve could be interpreted as that price of capital that would have to be paid to the representative agent to make him or her indifferent between their present portfolio, and buying another unit of capital, when they presently hold $k$ units of the asset. Equilibrium then dictates that these curves intersect at the equilibrium price and existing quantities of capital.

In contrast, the two-period-lived model described in this paper may be more appropriately characterized by Figure 5. The agents who are in the first period of their life will wish to purchase capital, and the demand curve reflects the quantity desired at different price levels by this group of individuals. Agents who are in the last period of their life will sell all assets at their disposal ( $\bar{k}$ units in the diagram) irrespective of the price that results. Hence the supply curve is vertical.

Elementary economics reveals that for a given increase in demand, the resulting price level will be higher in Figure 5 than in Figure 4. Hence, one might be inclined to state that the two-period-lived model would yield greater price variability. This would be true if one could guarantee that the demand shocks would be of the same magnitude.in both models. Unfortunately, these magnitudes will differ across different models, and their size must also be taken into consideration.

If agents were to live for $n$ periods, where $2<n<\infty$, instead of 2 periods, then in general the supply curve in Figure 5 would not be vertical because people who were in the $j^{\text {th }}$ period of their life, for $1<j<n$, would also be potential suppliers of assets. Hence, the tractability of the two-period models come with other 
characteristics which may not be present in models of longer-1ived agents.

Another characteristic of the two-period model employed in this paper is that the dividend yielded by capital has no effect upon the price of capital. This stresses the potential importance of other factors in the environment which affect these prices and certain minimizes the possible effects that dividends may have.

\section{Conclusion}

This paper is intended as a contribution to the literature which seeks to gain a better understanding of the determinats of asset prices. The models described herein imply that asset prices should reflect the underlying technology to which they are titles. Hence, a greater understanding of the determinants of these prices can only be gained if the technology as well as preferences are taken into consideration. The complication in the technology which was employed in this paper was adjustment costs in investment. Such a device has been employed in the study of the determinants of investment and therefore should be of no less importance in the study of capital asset prices. Different methods of modelling adjustment costs will imply different patterns of behavior for the price of capital as well as such variables as aggregate consumption and investment. Lastly, the importance of the two-period-lived nature of the utility function employed in this paper was discussed.

More complicated technologies which give an interesting relationship between the return of capital, and other factors in the environment (such as existing capital stock) could presumably be employed as well. In addition, it remains to be seen whether a more interesting pattern of behavior would emerge if agents were to have a planning horizon which was infinite, or at least greater than two periods. 


\section{FOOTNOTES}

${ }^{1}$ Non-capital income could also be included on the right side.

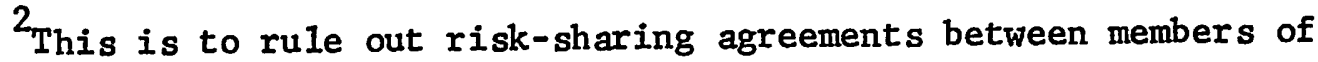
generations $(t)$ and $(t-1)$.

${ }^{3}$ All examples were derived by using a random sample of 5000 realizations.

${ }^{4}$ Models of $n$ period lived agents, where $2<n<\infty$ are also very difficult to solve. See Huffman [11] for a comparison of the two competing paradigms. 


\section{References}

[1] Bewley, T., "Thoughts on Tests of the Intertemporal Asset Pricing Mode1," Northwestern University, unpublished (1982).

[2] Brock, William A., "Asset Prices in a Production Economy," in The Economics of Information and Uncertainty, ed. J. J. McCall. Chicago: University of Chicago Press (1982).

[3] Fama, Eugene F., "Efficient Capital Markets: A Review of Theory and Empirical Work." Journal of Finance 25 (May 1970): 387-417.

[4] Flavin, Marjorie A., "Excess Volatility in Financial Markets: A Reassessment of the Empirical Evidence." Journal of Political Economy 91 (December 1983): 929-956.

[5] Grossman, Sanford F., and Shiller, Robert J., "The Determinants of the Variability of Stock Market Prices." American Economic Review 71 (May 1981): 222-227.

[6] Hansen, L. P. and Singleton, K. J. "Stochastic Consumption, Risk Aversion, and the Temporal Behavior of Asset Returns." Journal of Political Economy 91 (April 1983): 249-265.

[7] Hayashi, F., "Tobin's Marginal q and Average q: A Neoclassica1 Interpretation." Econometrica 50 (January 1982): 213-224.

[8] Huberman, G., "Capital Asset Pricing in an Overlapping Generations Model." Journal of Economic Theory 33 (August 1984): .232-248.

[9] Huffman, G. W., "Asset Pricing with Capital Accumulation." University of Western Ontario Working Paper (March 1983).

[10] Huffman, G. W., "Asset Pricing with Heterogeneous Agents." Unpublished (1985).

[11] Huffman, G. W., "The Representative Agent, Overlapping Generations, and Asset Pricing." University of Western Ontario Working Paper.

[12] Kleidon, A. W., "Bias in Small Sample Tests of Stock Price Rationality." University of Chicago Graduate School of Business Working Paper (Revised: May 1982).

[13] Kleidon, A. W., "Variance Bounds in a Simple Model of Asset Pricing: A Comment." University of Chicago Graduate School of Business Working Paper (Revised: May 1982).

[14] LeRoy, Stephen F., "Risk Aversion and the Martingale Property of Stock Prices." International Economic Review 14 (July 1973): 436-446. 
[15] LeRoy, Stephen F., "Expectations Models of Asset Prices: A Survey of Theory." Journal of Finance 37 (March 1982): 185-217.

[16] LeRoy, Stephen F., and LaCivita, C. J., "Risk Aversion and the Dispersion of Asset Prices." Journal of Business 92 (October 1981): 535-547.

[17] LeRoy, Stephen F., and Porter, Richard 0., "The Present-Value Relation: Tests on Implied Variance Bounds." Econometrica 49 (May 1981): 555-574.

[18] Lucas, Robert E., Jr., "Asset Prices in an Exchange Economy." Econometrica 46 (November 1978): 1429-1445.

[19] Merton, R. C., "An Intertemporal Capital Asset Pricing Mode1." Econometrica 41 (September 1973): 867-887.

[20] Michener, Ronald W., "Variance Bounds in a Simple Model of Asset Pricing." Journal of Political Economy 90 (February 1982): 166-175.

[21] Prescott, Edward D., and Mehra, Rajnish, "A Test of the Intertemporal Asset Pricing Model." Federal Reserve Bank of Minneapolis, Staff Report \# 81 (1982).

[22] Ross, S. A., "The Arbitrage Theory of Capital Asset Pricing." Journa1 of Economic Theory 13 (December 1976): 341-349.

[23] Scheinkman, J.A. and Weiss, L., "Borrowing Constraints and Aggregate Economic Activity." University of Chicago (1983).

[24] Shiller, R. J., "Do Stock Prices Move Too Much to be Justified by Subsequent Changes in Dividends?" American Economic Review 71 (June 1981): 421-436.

[25] Townsend, R., "Asset Return Anomalies: A Choice Theoretic, Monetary Explanation." Carnegie-Mellon University (Revised: June 1982).

[26] Tobin, James, "A General Equilibrium Approach to Monetary Theory." Journal of Money, Credit and Banking 1 (February 1969): 15-29. 


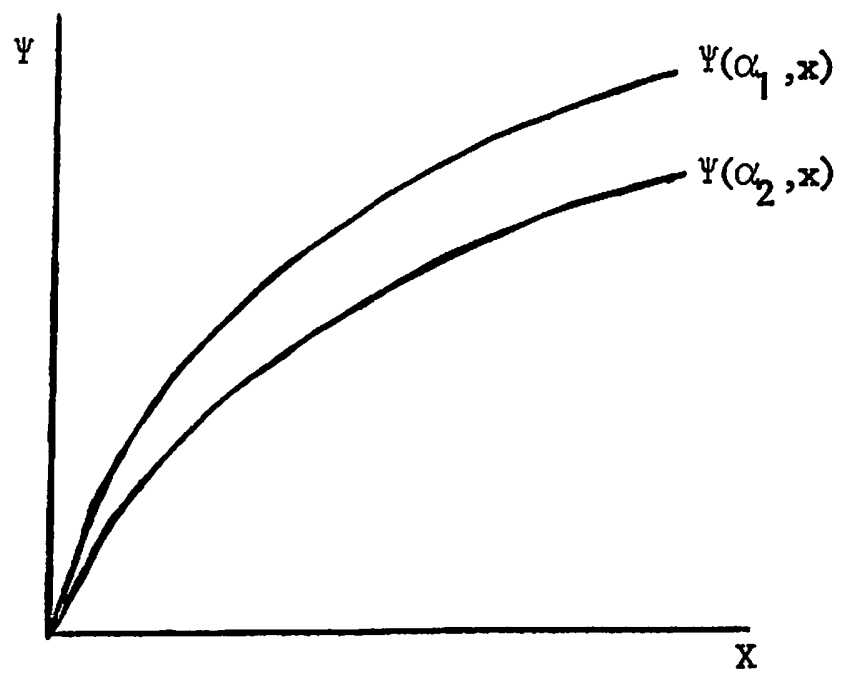

Figure 1

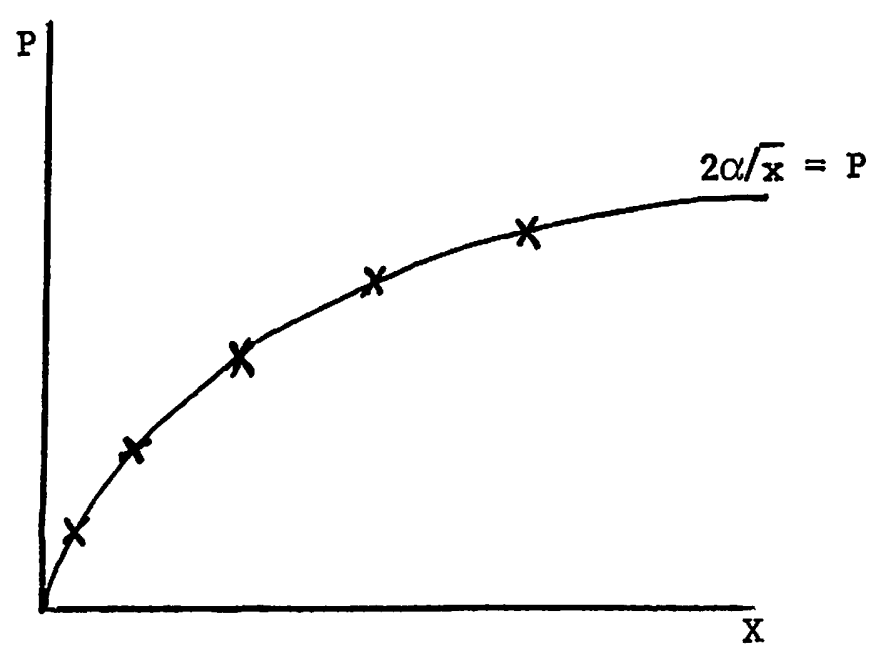

Figure 2

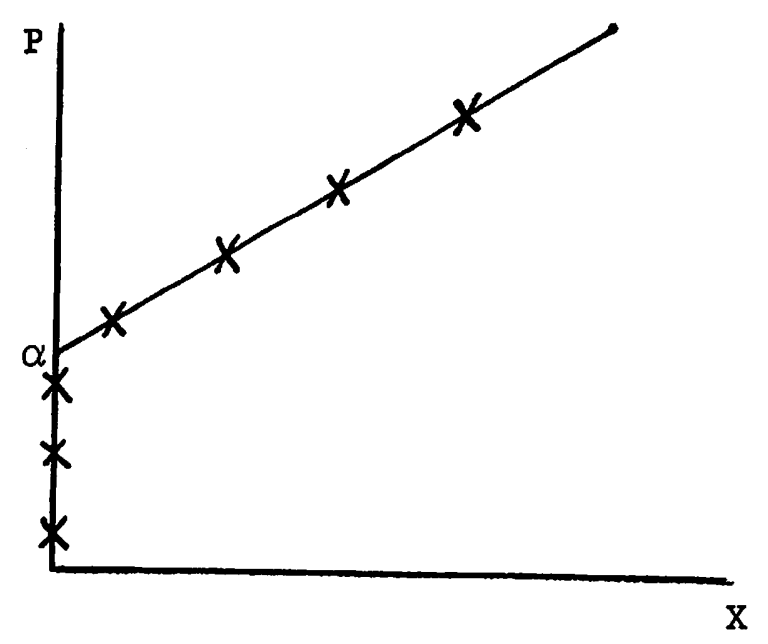

Figure 3 


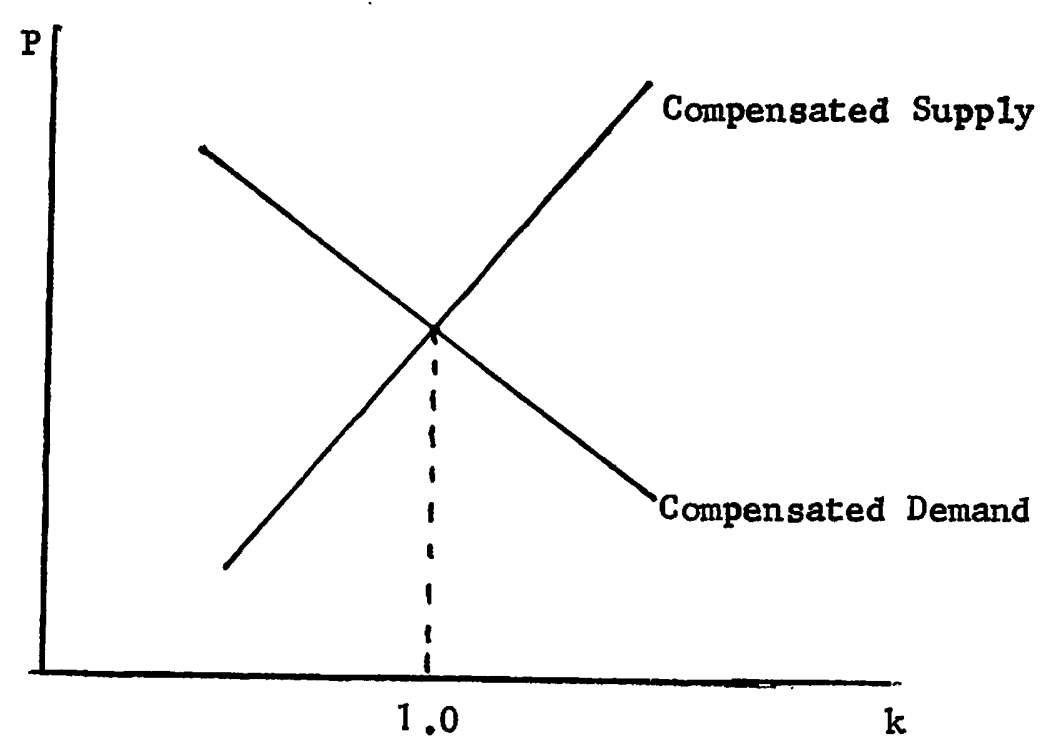

Figure 4

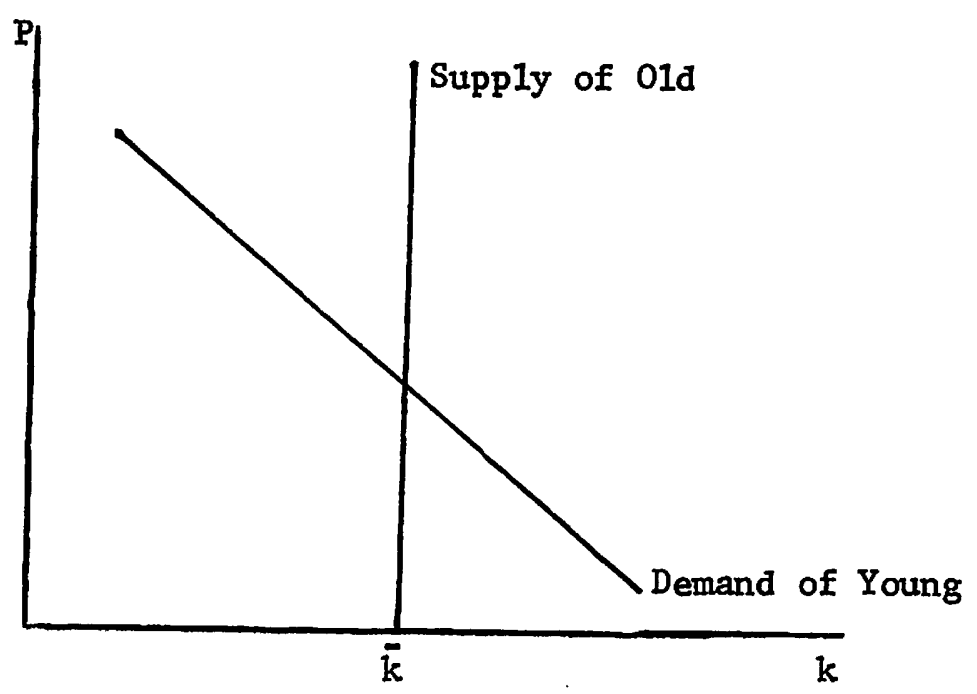

Figure 5 